Thorax (1950), 5, 59.

\title{
PARA-AMINO-SALICYLIC ACID (P.A.S.) AND STREPTO- MYCIN IN THE SURGICAL TREATMENT OF PULMONARY TUBERCULOSIS
}

BY

\author{
G. BIRATH, T. BRUCE, C. CRAFOORD, AND L. G. UGGLA \\ From Söderby Hospital for Tuberculosis, Uttran, Stockholm, Sweden*
}

When the value of P.A.S. and streptomycin began to be realized, there was at first an idea that the surgical treatment of pulmonary tuberculosis would glide into the background. The new drugs, however, did not render collapse therapy superfluous, and before long it was clear that one of the chief indications for the combined use of P.A.S. and streptomycin was precisely in the surgical treatment of tuberculosis. Thus, in 1947, opinions as to the value of streptomycin used in combination with the operative treatment of pulmonary tuberculosis appeared in several American publications. In the same year Glover and his co-workers described cases where combined surgical and antibiotic treatment had given very promising results. In 1948, Carstensen and Sjölin announced that patients in poor general condition, with simultaneous pulmonary and intestinal tuberculosis could, after P.A.S. therapy, be made fit for operation so that the lung disease could be treated by collapse therapy. An extensive investigation of the value of streptomycin combined with operation was carried out by Mulvihill and his co-workers in 1949. Up till now, however, a comparison of cases where both P.A.S. and streptomycin have been tried has been lacking.

\section{Plan of the Investigation}

In 1948 the value of R.A.S. and streptomycin in association with the operative treatment of pulmonary tuberculosis was investigated at Söderby Hospital. The patients who were regarded as probable candidates for surgical treatment were divided into two groups: (1) typical cases (T-group) and (2) border-line cases (B-group). In the T-group those patients were placed who presented the usual classical indications for surgical intervention. They were further divided into three subgroups, thus. Every third case was not treated with any drugs or antibiotics (control cases): every third case received $14 \mathrm{~g}$. of P.A.S. granulate (net weight of P.A.S. 10 g.) daily for one week before the first operation and from then onwards until two weeks after the last operation; every third case received, according to the same rules, $1 \mathrm{~g}$. streptomycin daily. The remaining patients who were under consideration for surgical treatment were assigned to

\footnotetext{
* The study was aided by a grant from the Swed ish National Association against Tuberculosis.
} 
the B-group (i.e., border-line cases). These patients were assessed as being doubtful candidates for surgical treatment because of the extent and type of their disease. Thus, the majority had exudative lesions, or they were febrile, or they had lesions in the other lung, and a few had already had collapse therapy applied upon the opposite side. These border-line cases were further divided into two subgroups, so that every other case received P.A.S. and the remainder were given streptomycin in the same dosage as for the typical cases. The treatment was given at least four to six weeks pre-operatively and was continued for at least four weeks after the last operation.

The series comprised altogether 106 patients, of whom 75 were intended for thoracoplasty, 26 for extrapleural pneumothorax, three for suction drainage by Monaldi's method, and two for open pneumonolysis. The division of the material into typical cases and border-line cases and by P.A.S. and streptomycin medication is shown below.

TABLE I

Distribution of the CaSes in the Various Groups

\begin{tabular}{c|c|c|c|c}
\hline \multicolumn{2}{c|}{$\begin{array}{c}\text { Thirty-nine Typical Cases } \\
\text { (T-group) }\end{array}$} & \multicolumn{2}{c}{$\begin{array}{c}\text { Sixty-seven Border-line Cases } \\
\text { (B-group) }\end{array}$} \\
\hline Untreated & P.A.S. & Streptomycin & P.A.S. & Streptomycin \\
\hline 11 & 14 & 14 & 35 & 32 \\
\hline
\end{tabular}

It will be seen that some patients, for various reasons, could not be investigated according to the plan outlined above.

\section{LABORATORY INVESTIGATIONS}

All cases have been examined according to the following programme.

Radiographic examination was carried out during the period of treatment at least every month and more often in connexion with operative procedures. All cases have been followed up for four months after the last operation.

Weight, sedimentation rate, and differential blood count (non-filament neutrophils) have been recorded before the beginning of treatment and thereafter every other week.

The amount of sputum has been measured during the entire period, but there is the usual degree of uncertainty in these measurements. The measurement given is the average amount per week.

Sputum was examined for tubercle bacilli, either by direct smear or by culture. Only the results of the direct smear investigations have been included. The number of tests has varied with the amount of sputum, which, especially after collapse operations. has been minimal, and sometimes non-existent. A weekly test has otherwise been the aim. 


\section{RESUlTS OF THE INVESTIGATION}

Observations from the pre-operative treatment of border-line cases will be discussed first. Then the findings of investigations carried out immediately before the first operation will be compared in border-line cases and typical cases. Clinical data from the first stage of the post-operative period will be given and comparisons will next be made between border-line and typical cases and between the P.A.S. and streptomycin groups. In the same way, observations of radiographic and sputum findings at the end of the investigation period, i.e., four months after the last operation ("final results"), will be accounted for in the different groups of patients.

Pre-operative P.A.S.- and Streptomycin-treated Border-line Cases.-The duration of the pre-operative treatment in B-group is in some degree dependent on the drug used. With streptomycin, we had to realize the fact that bacterial resistance might occur even after some few weeks of treatment. If the organisms become resistant the protective effect, especially when the operation is performed in several stages, is lost. This influenced us in shortening the pre-operative period of treatment in patients treated with streptomycin. In the case of P.A.S., there was no need of such precautions, and thus the treatment could be prolonged as desired. The average period of treatment for the 35 P.A.S. cases was 85 days and for the 32 streptomycin cases 44 days.

In Fig. 1 it can be seen that during the treatment there was a slight fall in temperature to $37.1^{\circ} \mathrm{C}$.

The blood sedimentation rate (Fig. 2) was moderately high before treatment, but after six weeks' therapy it had fallen to an average of $20-25 \mathrm{~mm}$. in one hour, roughly the same figures as in the immediate pre-operative period.

Non-filament neutrophils (Fig. 3), another expression of the toxicity of the disease process, were present in the P.A.S. cases before pre-operative treatment in the high average of $12.1 \%$ and in the streptomycin cases somewhat lower, $8.8 \%$. After six weeks of treatment, the average had fallen to almost normal values, $6.8 \%$ and $5.2 \%$ respectively, and immediately before operation it was within the limits of the normal.

The amount of sputum (Fig. 4) fell during treatment to rather small quantities, equal in both groups.

During the pre-operative treatment, the percentage of sputum-positive cases (Fig. 5) was gradually falling and immediately before operation it had decreased to $18 \%$ and $26 \%$ respectively.

As regards weight, there was a gain in the P.A.S.-treated cases as well as in the streptomycin cases during the period of pre-operative treatment; in the former, a mean of $1.40 \mathrm{~kg}$. and in the latter $1.95 \mathrm{~kg}$. After six weeks, the average increase in weight in the P.A.S. cases was $0.21 \mathrm{~kg}$. and in the streptomycin cases $1.83 \mathrm{~kg}$. Thus a more rapid gain seemed to take place where streptomycin was given. 


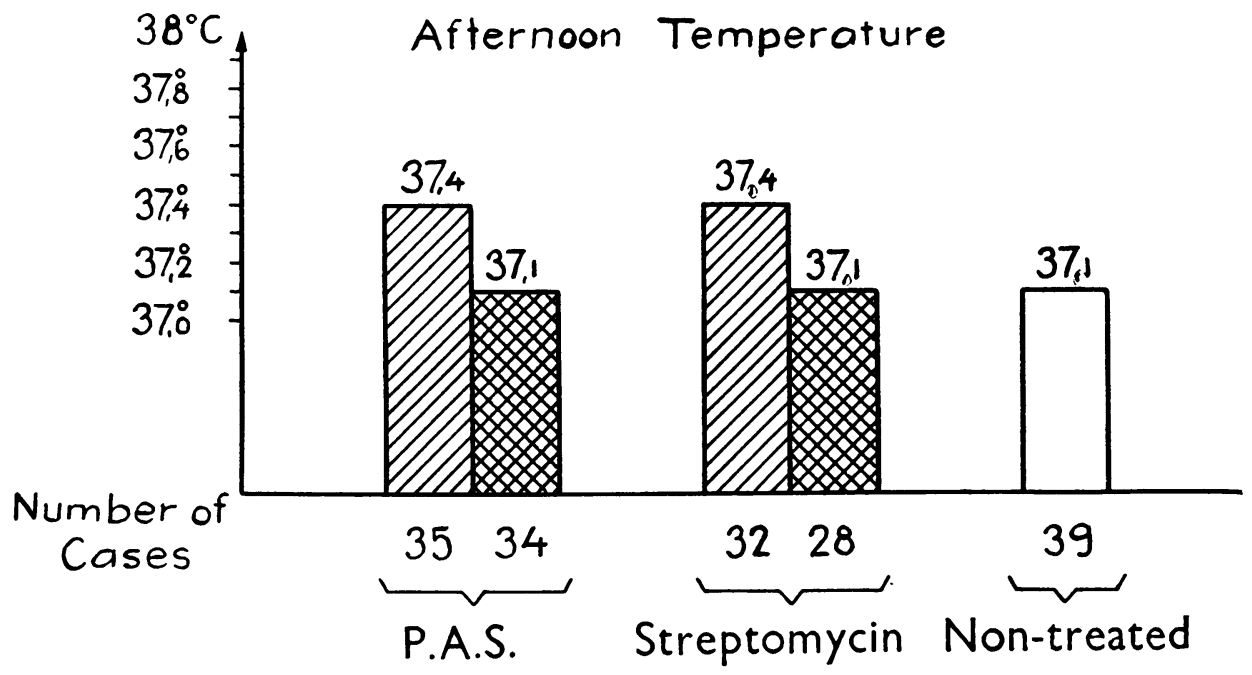

Fig. 1.

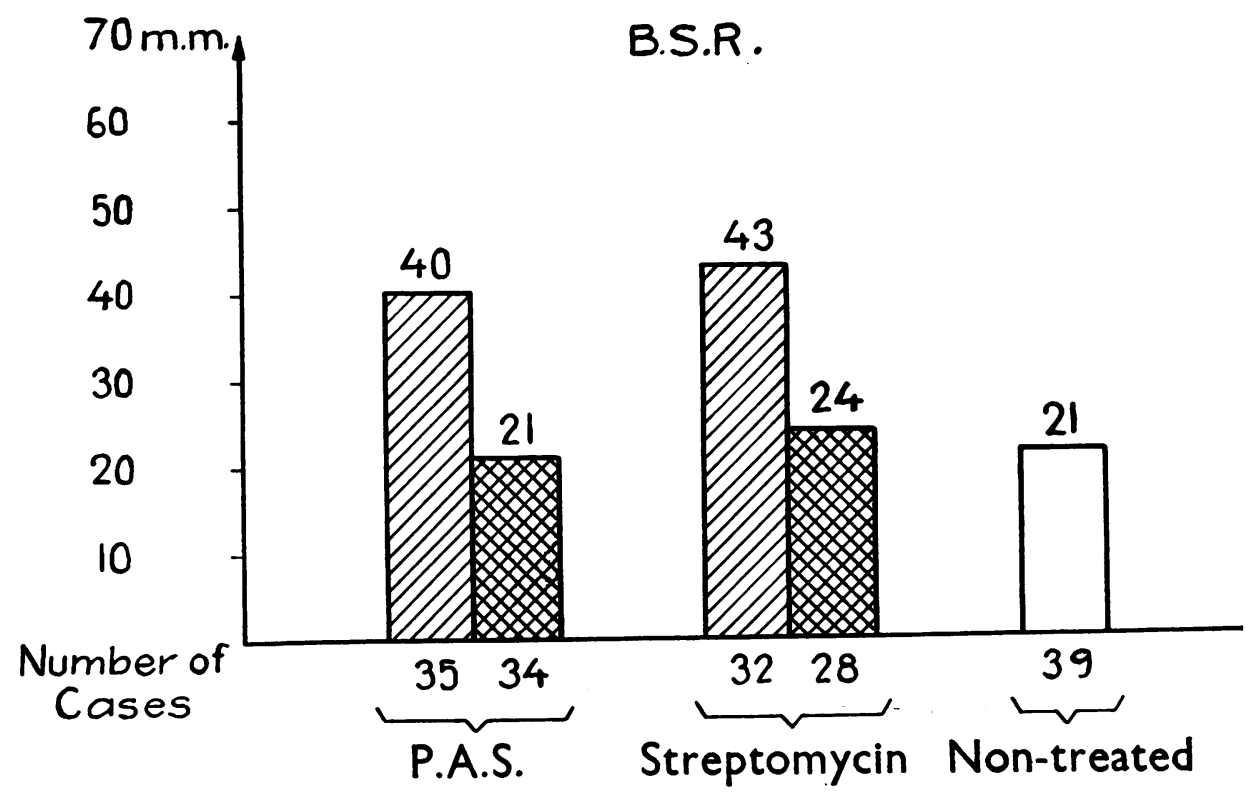

Fig. 2.

Figs. 1-4.-Result of pre-operative treatment in border-line cases, given as averages of afternoon temperature, blood sedimentation rate, percentage of non-filament neutrophils, and quantity of sputum before and after treatment, compared with typical cases immediately before operation. 
P.A.S. AND STREPTOMYCIN IN TUBERCULOSIS

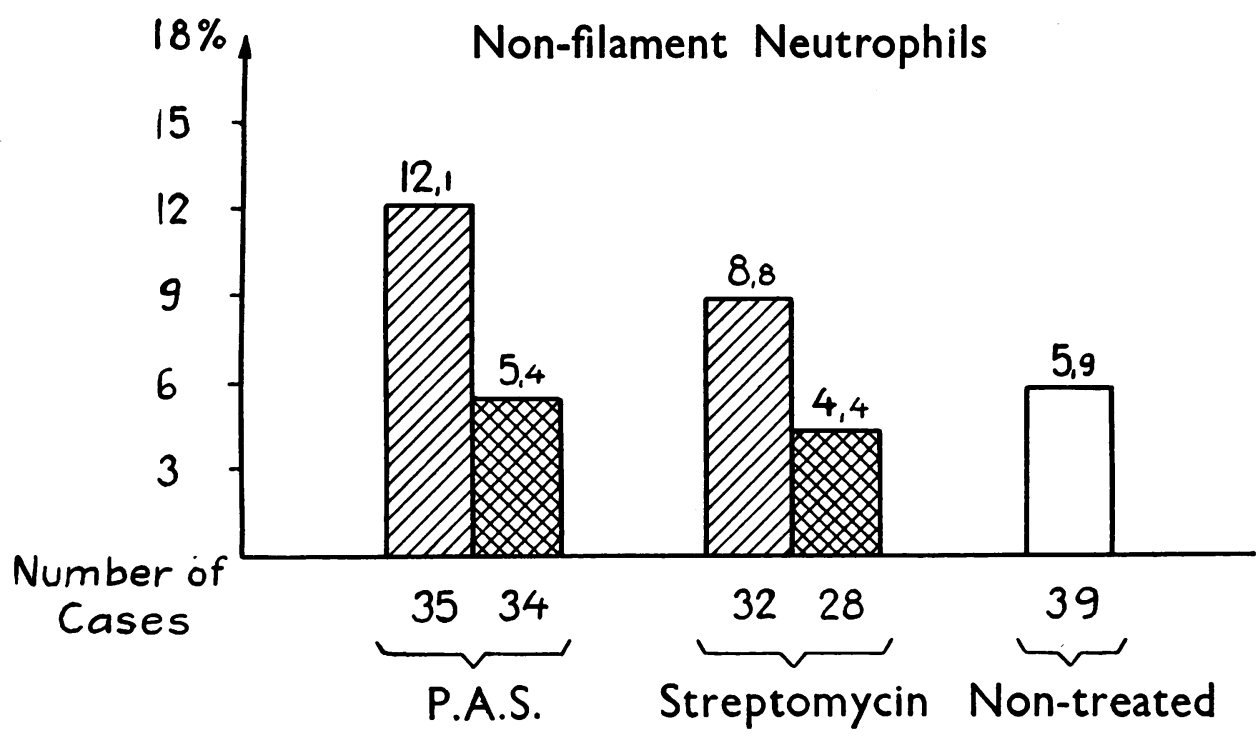

Fig. 3.

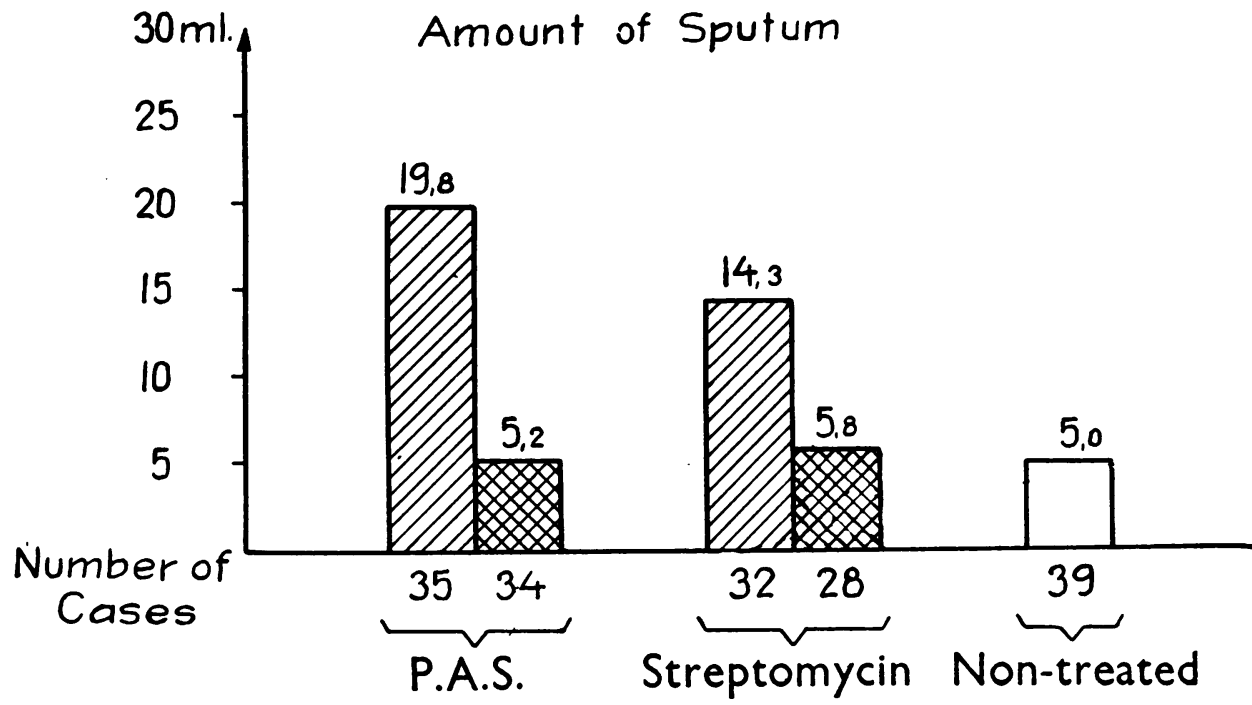

Fig. 4.

WA $=$ Borderline cases before treatment.

= Borderline cases after treatment

= Typical cases 


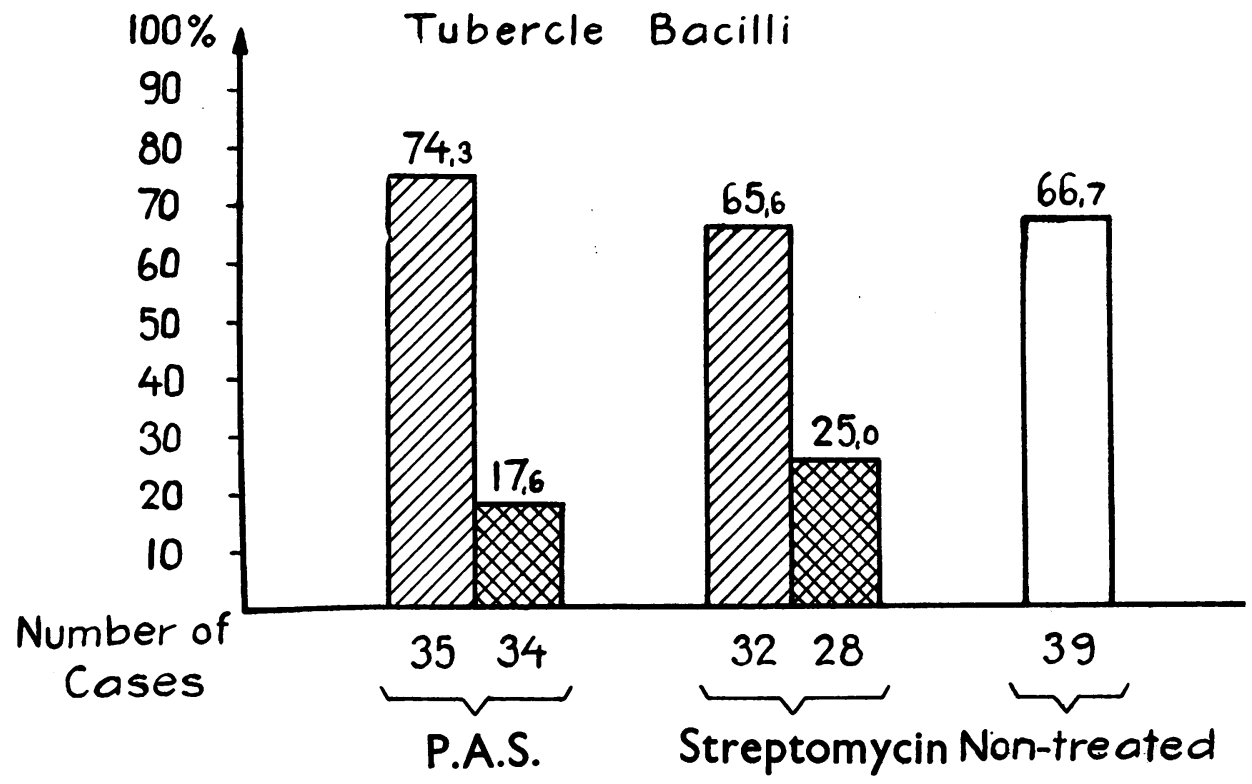

\section{$Z=$ Borderline cases before treatment \\ Borderline cases after treatment \\ $\square=$ Typical cases}

Fig. 5.-rercentage of sputum-positive cases before and after pre-operative treatment in the B-group and immediately before operation in the T-group.

The course of the disease as seen by radiographs is shown in Table II, where findings recording resolution and spread have been graded from I-III.

TABLE II

Changes in the Radiographs of B- and T-Groups During Pre-operative Treatment

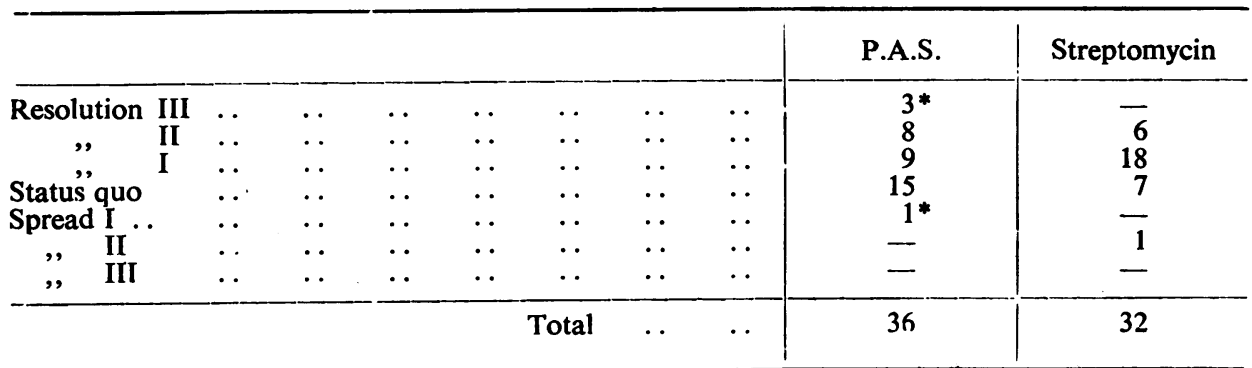

* The table comprises 36 P.A.S. observations, since in one case one lung showed resolution III and the other spread I. 
Radiological improvement is thus shown in $56 \%$ of the P.A.S. and $75 \%$ of the streptomycin group.

The course of the disease in two border-line cases, one P.A.S.- and the other streptomycin-treated, is shown in Figs. 6 and 7.

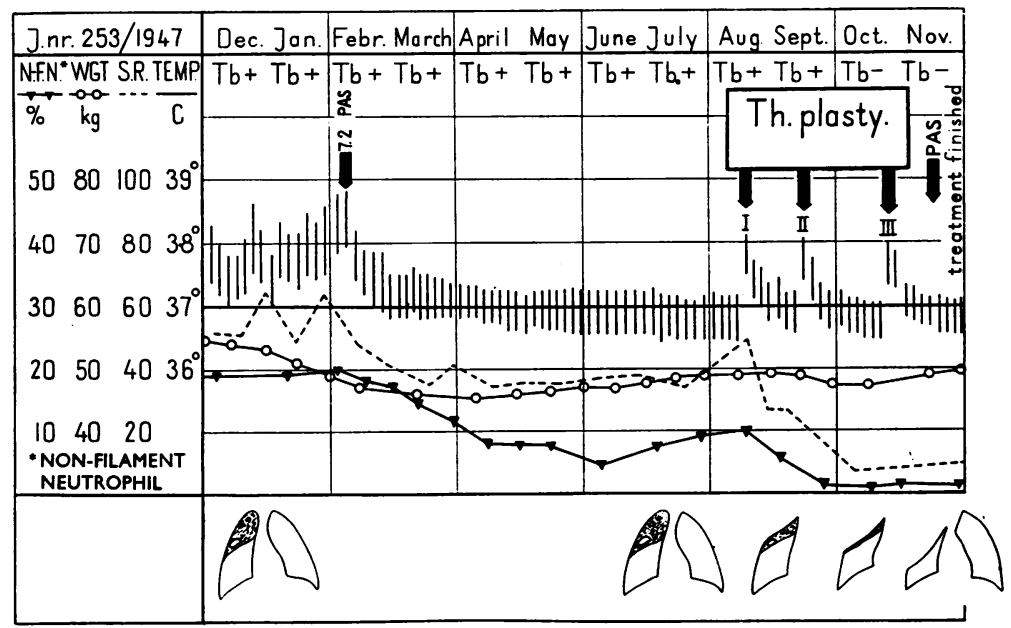

Fig. 6. - Chart of course of treatment in a P.A.S.-treated border-line case.

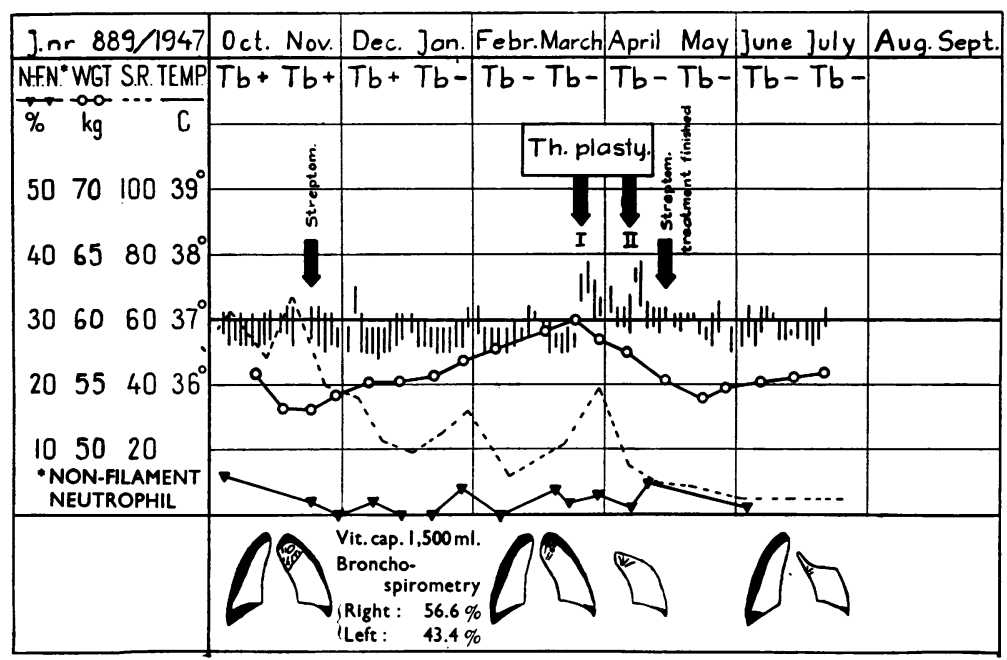

FIG. 7.-Chart of course of treatment in a streptomycin-treated border-line case.

These clinical data demonstrate that a considerable improvement took place in the pre-operative period. As the improvement was more rapid in the streptomycin cases (and this was especially obvious in radiographs), these patients could 
be operated upon earlier than those treated with P.A.S. But when P.A.S. medication had been continued for a longer period of time, the improvement in that group is seen to be quite as certain as after streptomycin treatment. The fact that the P.A.S. group includes cases where the radiographical improvement was ultimately more pronounced than in those patients who had received streptomycin may be the result of the longer average period of treatment. The drawbacks of the slower effects of P.A.S. are not so conspicuous as is the common appearance of bacterial resistance to streptomycin. We are of the opinion, therefore, that P.A.S., which did not seem to produce an increase of resistance on the part of the tubercle bacillus during our relatively short period of treatment, is the preparation of choice for use in preoperative therapy.

Comparison of Border-line and Typical Cases at the First Operation Period.An account has been given above of the improvement which began during preoperative treatment of B-group. The following is a comparison between B-group at the end of this period and T-group, where medication was begun before the operation period. The figures in Table III constitute percentages or averages for the whole group.

TABLE III

Differences Between B- and T-Groups Immediately Before Operation

\begin{tabular}{|c|c|c|c|c|}
\hline & & \multicolumn{2}{|c|}{$\begin{array}{l}\text { Border-line Cases } \\
\text { (B-group) }\end{array}$} & \multirow{2}{*}{$\begin{array}{c}\text { Typical Cases } \\
\text { (T-group) }\end{array}$} \\
\hline & & P.A.S. & Streptomycin & \\
\hline $\begin{array}{l}\text { Afternoon temperature }\left({ }^{\circ} \mathrm{C} .\right) \\
\text { Sedimentation rate }(\mathrm{mm} . \text { in } 1 \text { hour) }\end{array} \quad \ldots$ & $\begin{array}{l}\cdots \\
\cdots \\
\cdots \\
\cdots\end{array}$ & $\begin{array}{l}37.1 \\
21 \\
5.4 \\
5.2 \\
18\end{array}$ & $\begin{array}{c}37.1 \\
24 \\
4.4 \\
5.8 \\
26\end{array}$ & $\begin{array}{c}37.1 \\
21 \\
5.9 \\
4.9 \\
67\end{array}$ \\
\hline
\end{tabular}

The difference between border-line and typical cases at the beginning of the operation period is also illustrated by Figs. 1 and 2 .

It is thus apparent that border-line cases at the time of operation were so greatly improved with regard to temperature, percentage of non-filament neutrophils, sedimentation rate, and sputum production that they were on a par with the typical cases. As regards the patients who were sputum positive, the comparison is unfavourable to the typical cases. The border-line cases, among which were many patients who were originally very ill, improved to such an extent during pre-operative treatment that it was possible to undertake operation when they were apparently in as good condition as the typical cases.

Observations from the First Month of the Post-operative Period.-The series comprises now only 100 cases. Two patients, one P.A.S.- and the other streptomycintreated, refused operation. One patient had to be excluded because of allergy to streptomycin. Two patients, one P.A.S.- and the other streptomycin-treated, 
became worse during treatment and were excluded because they required combined chemotherapy. One streptomycin patient did not improve sufficiently to make operation possible.

Comparison will be made here between the immediate effect of the operations in the long-term treated B-group and the untreated or short-term treated T-group as a whole. The untreated cases alone are unfortunately too few to allow of comparison with the other cases.

In the immediate post-operative period, there was a maximum average temperature (Table IV) in the afternoon of the second day after operation varying between $38.2^{\circ} \mathrm{C}$. and $38.4^{\circ} \mathrm{C}$. The temperature then fell slowly, very uniformly

TABLE IV

Analysis of Clinical Data During the Post-operative Periods in All Groups

\begin{tabular}{|c|c|c|c|c|c|c|}
\hline & & \multicolumn{3}{|c|}{$\begin{array}{c}\text { Afternoon } \\
\text { Temperature }\left({ }^{\circ} \mathrm{C} .\right)\end{array}$} & \multirow{2}{*}{\begin{tabular}{|c}
$\begin{array}{c}\text { Sedimentation Rate } \\
\text { (mm./hr. according } \\
\text { to Westergren) }\end{array}$ \\
$\begin{array}{c}\text { After } \\
\text { 3-4 Weeks }\end{array}$
\end{tabular}} & \multirow{2}{*}{$\begin{array}{c}\begin{array}{c}\text { Non-filament } \\
\text { Neutrophils } \\
(\%)\end{array} \\
\text { After } \\
\text { 3-4 Weeks }\end{array}$} \\
\hline & & $\begin{array}{c}\text { 2nd day } \\
(\max .)\end{array}$ & $\begin{array}{l}\text { After } \\
1 \text { Week }\end{array}$ & $\begin{array}{c}\text { After } \\
4 \text { Weeks }\end{array}$ & & \\
\hline \multirow{4}{*}{$\begin{array}{l}\text { Border-line } \\
\text { Cases } \\
\text { (B-group) } \\
\text { Typical } \\
\text { Cases } \\
\text { (T-group) }\end{array}$} & \multirow{4}{*}{$\begin{array}{c}\left\{\begin{array}{c}\text { P.A.S. (28 cases) } \\
\text { Streptomycin } \\
\text { (25 cases) } \\
\text { P.A.S. (14 cases) } \\
\text { Streptomycir } \\
\text { (14 cases) } \\
\text { Untreated } \\
\text { (11 cases) }\end{array}\right.\end{array}$} & 38.2 & 37.6 & 37.3 & 32 & 5.4 \\
\hline & & $\begin{array}{l}38.3 \\
38.4\end{array}$ & $\begin{array}{l}37.8 \\
37.8\end{array}$ & $\begin{array}{l}37.2 \\
37.2\end{array}$ & $\begin{array}{l}38 \\
23\end{array}$ & 4.2 \\
\hline & & 38.4 & 37.7 & 37.2 & 31 & 4.0 \\
\hline & & 38.4 & 37.5 & 37.1 & 35 & 6.3 \\
\hline
\end{tabular}

in the P.A.S.- and streptomycin-treated cases, and after one week it reached the mean of $37.5^{\circ} \mathrm{C} .-37.8^{\circ} \mathrm{C}$. in the afternoon. During the fourth post-operative week, the mean afternoon temperature lay between $37.1^{\circ} \mathrm{C}$. and $37.3^{\circ} \mathrm{C}$. There is no difference either between the effect of the drugs or between the $T$ - and B-groups.

The sedimentation rate (Table IV) during the post-operative period (after the one-stage operations and after the last stage in other cases) varied in the third to fourth weeks between $31-38 \mathrm{~mm}$. in one hour, except in the P.A.S. cases of the T-group, where the value was $23 \mathrm{~mm}$.

The proportion of non-filament neutrophils (Table IV) in the third to fourth week showed no significant differences and varied on an average from $4.0 \%$ to $6.3 \%$.

Loss of weight is also an expression of the toxicity of the disease process at the time of operation. It was calculated after the one-stage operations and after the last stage in the other cases. The P.A.S. cases in the T-group showed an average loss of weight of $2.9 \mathrm{~kg}$. after three to four weeks, the streptomycin cases $3.1 \mathrm{~kg}$., and the untreated cases $2.8 \mathrm{~kg}$. In the B-group the loss after the same time was $2.7 \mathrm{~kg}$. in the P.A.S. and $2.9 \mathrm{~kg}$. in the streptomycin cases. 
These figures justify the conclusion that no obvious differences concerning the factors investigated existed in the various groups during the post-operative period.

In association with operative procedures, signs of certain complications appeared on radiological examination. Demonstrable lesions of a transient nature and contralateral spread were equally divided amongst the various groups.

Findings Four Months after the Last Operation ("Final Results").--During the post-operative period, some further patients had to be excluded from the investigation. The course of the disease in three cases with Monaldi suction drainage became very protracted, and resort had to be made to combined chemotherapy. In one P.A.S. case, the post-operative course appeared especially critical to begin with, and in this case streptomycin had to be used. Infection of the operation wound led to combined chemotherapy being used in three P.A.S. and one streptomycin case. (These cases later completed treatment with good results.) The uneven division between the two groups of the four last-named patients bears out the stronger protective effect of streptomycin compared with that of P.A.S. in other infections.

The results of treatment as they appear from radiological findings in the typical cases are set out in Table V.

TABLE V

Operation Results in T-Group with Reference to Radiographs

\begin{tabular}{|c|c|c|c|}
\hline & Untreated & P.A.S. & Streptomycin \\
\hline 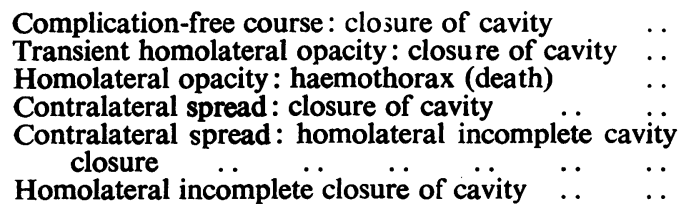 & $\begin{array}{l}8 \\
2 \\
- \\
- \\
1\end{array}$ & $\begin{array}{r}11 \\
\frac{1}{1} \\
-1\end{array}$ & $\begin{array}{l}\frac{12}{1} \\
1 \\
-\end{array}$ \\
\hline Total & 11 & 14 & 14 \\
\hline
\end{tabular}

In two of the 39 cases the original cavity in the operated lung was incompletely closed after four months. One of these patients belonged to the untreated control group and the other to the P.A.S. group. The streptomycin-treated patient, in whom homolateral spread and haemothorax, as seen in Table V, developed, died a few days after operation as a result of haemorrhages. Contralateral spread took place in three cases, one from each group. In all three cases spread consisted of minor patchy infiltrations, which did not demand active treatment, but which, with continued observation, underwent resolution. Radiologically demonstrable complications were thus found in all three groups.

The later post-operative course did not show such variations as would provide a basis for the belief that short-time chemotherapy during surgical treatment gave improved results. Reservations must be made for the small size of the groups. 
The results, as they appear from radiological findings in the border-line cases, can be seen in Table VI.

TABLE VI

Operation Results in B-Group With RefERence to Radiographs

\begin{tabular}{|c|c|c|c|c|c|}
\hline & & & & P.A.S. & Streptomycin \\
\hline $\begin{array}{l}\text { Complication-free course: closure of cavity } \\
\text { Transient homolateral opacity: closure of cavity } \\
\text { Incomplete closure of homolateral cavity } \\
\text { Homo- and contralateral progress }\end{array}$ & $\begin{array}{l}\cdots \\
\cdots \\
\cdots\end{array}$ & $\begin{array}{l}\cdots \\
\cdots \\
\cdots \\
\cdots\end{array}$ & $\begin{array}{l}\cdots \\
\cdots \\
\cdots\end{array}$ & $\begin{array}{c}24 \\
1 \\
2 * \\
1\end{array}$ & $\frac{22}{2}$ \\
\hline & Total & & $\cdots$ & 28 & 25 \\
\hline
\end{tabular}

* In one case a third stage of thoracoplasty could not be carried out as planned because of a threatened ventilation insufficiency.

A complication-free late course with closure of cavity after four months was obtained in 46 cases, 24 P.A.S.- and 22 streptomycin-treated. There was incomplete closure of cavity after four months in two P.A.S.- and two streptomycin-treated patients ; one of the two P.A.S. cases was not completed, because a third stage thoracoplasty, which was necessary for cavity closure, could not be carried out owing to respiratory insufficiency. In direct association with operation, an exudative tuberculosis, which resulted in death, developed in one streptomycin case. In one P.A.S. case, a fourth stage of thoracoplasty could not be carried out because of homo- and contralateral spread and poor general condition. There is no difference with regard to the results of treatment as they appear from the radiological findings between the P.A.S. and streptomycin groups. Spread of the tuberculous process rarely occurred even in the frail patients during the postoperative period.

As regards examination of sputum, we stress that all the typical and border-line cases, which post-operatively showed transient radiological opacities or contralateral spread, had tubercle bacilli in the sputum when they underwent operation. Sputum examination up to four months after the last operation showed freedom from bacilli in all cases where radiological closure of cavity was present. In none of the typical cases was a positive sputum found for four months after the operation period. Of the border-line cases, we had at the corresponding time only four with tubercle bacilli in the sputum: these can be found again amongst those in whom radiological examination showed progress or incomplete closure of cavity.

\section{DISCUSSION}

We have not been able to demonstrate better results of treatment in the chemotherapy group than in the control cases. But in three of the 39 typical cases, post-operative contralateral spreau occurred, while a similar extension of the disease affected only two of 50 border-line cases. This difference should be taken into account and the fact that at the time of operation the typical cases were sputum-positive to a numerically greater extent than were the border-line cases. Spread only occurred in those patients whose sputum was positive at the time 
of operation. The lengthy medication of the border-line cases must be considered to have had a beneficial therapeutic effect, and thereby to have decreased the risks of a post-operative spread of the disease. Seen against the background of the favourable results in the border-line cases, it must be presumed that the medication of the typical cases was too brief to provide an optimum protection during the post-operative phase. On these grounds, and because it is well known that even with a cautious approach to operative intervention surprising spreads can sometimes occur in association with the lowering of the general condition which operation trauma produces, the use of a drug with an inhibiting effect on the disease is to be recommended. Pre-operative treatment can, of course, even in typical cases, bring about sputum conversion in some patients by the time of operation; this implies a decided advantage.

All the patients with typical indications for surgical treatment, with the exception of one who died shortly after operation, were able to complete the treatment without difficulty, and were brought through the operation period according to plan. That some border-line cases had to be excluded from this investigation, because resort had to be had to combined chemotherapy for various reasons, is probably an expression of lower powers of resistance in that group.

It is very encouraging that the border-line cases could undergo operative treatment so well without complications. Although in certain of these cases the risks of operation could have been taken even without chemotherapy, the majority of this group, as experience has shown, could not have been surgically treated without rapid deterioration. As for each year before the introduction of chemotherapy the number of operated patients at this hospital was only insignificantly greater than that of the typical cases in this investigation (which also covers one calendar year), it would appear that the greater number of border-line cases, that is about half this series, consists of patients who, thanks to chemotherapy, have come within the reach of surgical collapse treatment. Chapman and his co-workers have likewise announced (1949) that they found that streptomycin therapy led to a doubling of the number of patients for whom surgical measures, especially thoracoplasty, could be reasonably undertaken.

\section{ConCLUSIONS}

In the report of the Council on Pharmacy and Chemistry in October, 1948, a warning is given of the development of resistance to streptomycin therapy in conjunction with classic thoracoplasty. As far as the Americans were concerned, the indications for pre-operative treatment, without ready access to P.A.S., were otherwise. We consider preventive therapy to be almost always indicated before operation, even in typical cases. In Sweden we attach great weight to the observation that pre-operative therapy resulted in a significant number of cases with negative sputum at the time of surgical intervention. As our investigation has given results approximately as good with preventive P.A.S. as with streptomycin medication, we now begin pre-operative treatment, almost without exception, with P.A.S. We also take into account its lesser tendency to produce a rapid increase of resistance, and with lengthy treatment it is less liable to provoke troublesome toxic symptoms. Also it is desirable to hold the most efficacious 
preparation in reserve in the event of possible complications. Further it appeared important for us, as a result of hypersensitivity amongst the nursing staff, to be restrictive in the use of streptomycin therapy. These reactions are now, with the use of dihidrostreptomycin, less frequent.

The pre-operative period of treatment is never less than four to six weeks, often considerably longer, perhaps three to six months, until the temperature becomes normal, the sedimentation rate falls, the non-filament neutrophils decrease, sputum production lessens, the weight increases, the lung process shows radiological regress, and the patient appears to be so much improved that he can be operated on according to typical indications, or with insignificantly increased risk. The entire P.A.S. treatment (pre- and post-operative) seldom lasts for less than three months. With lengthy pre-operative medication and operation in several stages the duration of treatment is considerably longer and is terminated, at the earliest, one month after the last operation. If we judge the situation, with regard to the approaching operation, still to be unstable, streptomycin is also given one to two weeks before the surgical procedure is begun; if the condition is judged to be more stable, streptomycin is given first if the post-operative course shows any noteworthy deviation from the normal. In cases where operation is planned we do not consider combined P.A.S. and streptomycin therapy to be suitable at an early stage because a bacterial resistance to the latter drug can develop by the time of operation, when the patient faces the most critical stage in his treatment. Such an opinion agrees also with the American observations that, if streptomycin only is available, that preparation should not be used pre-operatively in typical cases.

We consider treatment with chemotherapy and antibiotics in combination with surgical collapse measures in pulmonary tuberculosis, according to the lines sketched in this paper, to be justified by the results of the investigations. Experience during 1949 also vouches for the suitability and correctness of this mode of procedure. Even if combined chemotherapy has its scientific justification and a certain range of indications, the cases where surgical collapse measures can be considered fall to a great extent outside these indications, at least during the pre-operative phase of treatment. As surgical procedures only create certain improved conditions for healing, the importance of having, in the event of a possible relapse of the disease, a part of the therapeutic arsenal unused should not be under-estimated.

\section{SUMMARY}

One hundred and six patients have been classified into 39 typical and 67 border-line cases determined by suitability for various surgical procedures.

The border-line cases were treated pre-operatively with P.A.S. (35 cases) or streptomycin ( 32 cases), by chance allotment of the drugs, for an average of 85 and 44 days respectively, and then throughout the period of operation, finishing about one month after the last surgical procedure.

The typical cases were divided by chance into three groups, the first and second being treated with P.A.S. and streptomycin respectively, for one week before operation to two weeks after this period. The third group had no chemotherapy. 
The effect of P.A.S. and streptomycin pre-operative treatment was similar in the border-line cases but was more rapid when streptomycin was used. The toxic cases in this group were converted by treatment to equally good subjects for operation as the typical cases, and, as regards sputum conversion, they were even more favourably placed.

There was no evident difference between typical and border-line cases as regards the immediate post-operative reaction.

In seven of the 39 typical cases, extension of the disease occurred, homolaterally or contralaterally, fairly equally distributed in the three groups. Only three of the 53 operated border-line cases were complicated by spread (two P.A.S. and one streptomycin case). Cavity closure failed in two typical and four borderline cases.

We consider the investigation to have proved that border-line cases, preoperatively treated with chemotherapy, can undergo surgical treatment with insignificant risks of post-operative complications. P.A.S. is suggested as the drug of choice in preparing cases for operation, with streptomycin as an adjunct in unsuccessful cases or in post-operative spread.

\section{REFERENCES}

Carstensen, B., and Sjölin, S. (1948). Svenska Läkartidn., 45, 729.

Chapman, P. T., O'Brien, E. J., O'Rourke, P. V., and Douglas, B. (1949). J. thorac. Surg., $18,15$. Council on Pharmacy and Chemistry (1948). J. Amer. med. Ass., 138, 584.

Glover, R. P., Clagett, O. T., and Hinskaw, H. C. (1947). Amer. Rev. Tuberc., 55, 418.

Mulvihill, D. A., Miscall, L., Klopstick, R., and Bitsack, J. (1949). J. thorac. Surg., $18,1$. 